\title{
Dynamic Characteristics and Processing of Fillers in Polyurethane Elastomers for Vibration Damping Applications
}

\author{
A. R Mackintosh ${ }^{1 *}$, R A Pethrick ${ }^{1}$ and W M Banks ${ }^{2}$. \\ 1- WestCHEM, Department of Pure and Applied Chemistry, University of Strathclyde, \\ Thomas Graham Building, 295 Cathedral Street, Glasgow G1 1XL \\ and \\ 2- Department of Mechanical Engineering, University of Strathclyde, \\ James Weir Building, 75 Montrose Street, Glasgow G1 1XJ.
}

* - To whom communications should be addressed

E-mail:- $\quad$ allan.mackintosh@strath.ac.uk

Fax $\quad 01415484822$

Tel no:- 01415482795

Keywords:- polyurethane elastomers, fillers, wollastonite, barium sulphate, processing, relaxation.

Address for correspondence:- Department of Pure and Applied Chemistry, University of Strathclyde, Thomas Graham Building, 295 Cathedral Street, Glasgow G1 1XL

\begin{abstract}
Polyurethane elastomers have the potential of being used to reduce vibrational noise in many engineering applications. The performance of the elastomer is directly related to matching the nature of the mechanical loss characteristics to the frequency and temperature dependence of the source of the vibration. Materials with a broad frequency response and good mechanical properties are desirable for situations were load bearing and isolation becomes an issue. Because automobile, and other related vehicles operate over a broad temperature range, it is desirable for the damping characteristics of the elastomer to ideally
\end{abstract}


be independent of temperature and frequency. In practice, this is not possible and the creation of materials with a broad spectrum response is desirable.

In this paper, the effects of various fillers on the breadth and temperature dependence of the vibration damping characteristics of a filled and crosslinked polyurethane elastomer are explored. The fillers studied are wollastonite, barium sulphate and talc. These materials have different shapes, sizes and surface chemistry and undergoe different types of interaction with the matrix. The vibration damping characteristics were further varied by the use of a crosslinking agent.

Data presented on the rheological characteristics indicate the strength of the filler -polyol interactions. Dielectric relaxation and dynamic mechanical thermal analysis demonstrate the way in which changes in the type of filler, concentration and amount of crosslinker lead to changes in the location and breadth of the energy dissipation process in these elatomers. The vibration damping characteristics of a selected material are presented to demonstrate the potential of these materials.

\section{INTRODUCTION}

Vibrational damping is a problem encountered in a variety of different ways and is particularly important where noise abatement is an issue. The approach which is adopted will depend on the details of the particular application and whether or not the damping system is part of a load bearing structure. Generally, vibration can be reduced using various anechoic coatings but the materials from which these are created are often non load bearing [1]. Foamed polyurethane - PU materials - are commonly used for car seats and their damping characteristics have been extensively investigated [2-4]. In general, the damping characteristics correlate well with the mechanical energy dissipation characteristics of the material. Matching the maximum energy loss with the vibrational maximum frequency leads to an optimum design for the damping characteristics of the system. In the case of foams, the added complication arises that the level of compression can influence the energy dissipation characteristics. 
Solid PUs can be used directly as part of vibrational damping systems where load-bearing characteristics are important. There are at least two approaches to the problem of vibration damping; firstly, constrained layer damping in which an intermediate material is used to couple a high modulus layer to the substrate to be damped and secondly, surface layer damping where the coating attempts to remove the energy through a dissipative process. [512]. In both cases the damping characteristics are dictated by the energy dissipation characteristics of the polymer used. In this paper, the focus will be on the design of the material which can be used with either approach.

A large number of polymer systems have been investigated in the context of energy damping media and include epoxy, [5,11] epoxy/carbon fibre [5], polymethylmethacrylate - PMMA [6,9], polytetrafluoroethylene - PTFE [6] and nylon 6,6' [10] with varying degrees of success. PU systems have a significant advantage for energy damping applications in that it is relatively easy to change the formulation of the elostomer to achieve the desired match between energy loss and the vibration characteristics of the system concerned $[8,11]$ The damping characteristics of PUs can be varied by changing the isocyanate composition and type of diol to yield materials with different damping characteristics. $[8,13]$. However, the breadth of the loss peak for the typical PU is relatively narrow which imparts a significant temperature dependence of the damping behaviour. In order to use PUs for load bearing applications it is desirable to have a material with a high modulus yet retain the high loss characteristics. These are apparently contradictory requirements but can be designed into a material if phase separation occurs $[14,15]$. Additional increases in the modulus can be achieved by the incorporation of fillers [5]. The effects which will be produced will depend on the shape, volume fraction and surface chemistry of the filler used [5]. This paper describes a study in which the effects of incorporation of talc, silica, wollastonite and barium sulphate on the damping characteristics of a typical PU are explored. An additional variable explored is the effect of change in the crosslink density by the additional of a poly functional alcohol to the formulation. 
The fillers investigated have the following characteristics. Wollastonite is a natural calcium meta-silicate $\left(\mathrm{CaSiO}_{3}\right)$, formed by the metamorphism of siliceous limestone at temperatures around $450^{\circ} \mathrm{C}$ and higher [16]. Wollastonite is an example of a tri-clinic crystal with no symmetry elements. The surface of wollastonite readily absorbs water and hydroxylated by the $\mathrm{Ca}^{2+} / 2 \mathrm{H}^{+}$exchange reaction resulting in a surface characterized by a twisted, three silica tetrahedra unit. The chains formed by these silica tetrahedral are connected side by side through calcium in octahedral coordination and results in wollastonite growing as acicular crystals, having a high density and modulus (16). Densified hydrophilic fused silica, AEROSIL ${ }^{\circledR} 200 \mathrm{VV} 50$ has a specific surface area of $\sim 200 \mathrm{~m}^{2} / \mathrm{g}$ and is spherical in structure. Talc is hydrated magnesium silicate and usually has a distribution of particle sizes. Barium sulphate has a nodular particle structure, which is processed from Barytes ore to have a $\mathrm{BaSO}_{4}$ content of $86.9 \%$.

The paper explores the rheological characteristics of the polyol filled resins as a means of characterising the nature of the dispersion achieved and the strength of the interactions between polyol and filler. Dielectric relaxation and dynamic mechanical thermal analysis are used to demonstrate the way in which formulation changes influence the breadth and location of the energy loss processes. Finally a study of the damping characteristics of one of the materials will be presented to show how these materials may be used in vibration damping applications.

\section{EXPERIMENTAL DETAILS}

\subsection{Materials}

The polyurethane elastomers - PUs, were synthesised using poly(tetra methylene glycol) PTMEG, with $\mathrm{Mn} \sim 1000$, mpt $\sim 32^{\circ} \mathrm{C}$ and equivalent weight of $498 \mathrm{~g}$, supplied by BASF; Trimethylopropane -TMP, as a cross linker agent, $\mathrm{mpt} \sim 56^{\circ} \mathrm{C}$ and equivalent weight of 144g, supplied by Aldrich. Two methylenediphenyldisocynates -MDI were used; Hyperlast M143 and Suprasec 5005 with isocyanate equivalents of 2 and 2.7 respectively. The Hyperlast MDI was pre-polymerised at a 2:1 ratio with the poly(tetra-methylene glycol) to yield an average functionality of two. The Suprasec 5005 is a polymeric MDI. The details of the fillers used, their source and characteristics are summarised in Table (1). 


\begin{tabular}{|l|l|l|l|l|}
\hline Material & Supplier & $\begin{array}{l}\text { Mean } \\
\text { particle size }\end{array}$ & $\begin{array}{l}\text { Particle } \\
\text { Shape }\end{array}$ & $\begin{array}{l}\text { Density } \\
\mathrm{g} / \mathrm{cm}^{3}\end{array}$ \\
\hline Wollastonite & $\begin{array}{l}\text { Boud } \\
\text { Minerals }\end{array}$ & $45 \mu \mathrm{m}$ & $\begin{array}{l}\text { Fibre aspect } \\
\text { ratio 20:1 }\end{array}$ & 2.6 \\
\hline $\begin{array}{l}\text { Barium } \\
\text { Sulphate }\end{array}$ & $\begin{array}{l}\text { Boud } \\
\text { Minerals }\end{array}$ & $12.1 \mu \mathrm{m}$ & Nodular & 4.4 \\
\hline Silica & Degussa & $12 \mathrm{~nm}$ & n/a & 1.35 \\
\hline Talc & $\begin{array}{l}\text { Viaton } \\
\text { Industries }\end{array}$ & $15 \mu \mathrm{m}$ & Lamellar & 2.7 \\
\hline
\end{tabular}

Table (1) Characteristics of fillers used in creating the composite PU elastomers.

\subsection{Synthesis of polyurethane elastomeric materials}

The PTMEG and TMP, were heated to $+60^{\circ} \mathrm{C}$ and degassed for 20 minutes at $<1$ mbar. The fillers were added and the mix stirred under vacuum for 10min. The isocyanate, Hyperlast M143 or Suprasec 5005, were added at the stochiometric ratio, mixed at room temperature under vacuum, for $12 \mathrm{~min}$, and then poured into the mould. The mould was constructed of mild steel, with a base plate $1 \mathrm{~cm}$ thick. Side bars of $10 \mathrm{~mm}$ x $10 \mathrm{~mm}$ are added to create a rectangular test specimen of dimensions $80 \mathrm{~mm} \times 100 \mathrm{~mm} \times 10 \mathrm{~mm}$. The cure temperature was $60^{\circ} \mathrm{C}$ and cure occurred over a period of 16 hours. The amount of filler was recorded as the volume percentage of poly(tetramethylene glycol) used as the dispersion phase.

\subsection{Rheological measurements}

Rheological measurements were carried out using a CSL-2 TA instrument with a $2 \mathrm{~cm}$ parallel plate with a $500 \mu \mathrm{m}$ gap at $40^{\circ} \mathrm{C}$. Care was taken to ensure that the fluid filled the gap at all times.

\subsection{Dielectric relaxation measurements}

Thin films for dielectric measurements were created by pouring the PU mixture onto PTFE coated glass and uniform films were created using a spreader bar. Aluminium electrodes were evaporated onto the samples using an Edwards Coating System E306A. A Novocontrol frequency response analyser was used to cover the frequency range $0.1 \mathrm{~Hz}$ to $6.5 \times 10^{5} \mathrm{~Hz}$ and the temperature was controlled to better than ${ }^{ \pm} 0.5^{\circ} \mathrm{C}$. 


\subsection{Dynamic Mechanical Thermal Analysis - DMTA.}

Dynamic mechanical measurements were conducted using a Polymer Laboratories Ltd DMTA. Rectangular samples $10 \mathrm{~mm}$ x $20 \mathrm{~mm}$ and $\sim 2 \mathrm{~mm}$ thickness were clamped using a single cantilever mode of action and knife-edge clamping arrangement with a clamping torque of $40 \mathrm{Nm}$. The scanning frequency was $10 \mathrm{~Hz}$ and the samples were re-clamped at low temperatures to minimise slippage. In the case of multi-frequency DMTA, frequencies of $0.3,3,10$ and $30 \mathrm{~Hz}$ were used.

\subsection{Optical microscopy}

To assess the shapes of the fillers optical microscopy was performed on samples deposited on slides. The wollastonite samples were prepared in acetone and placed on a glass slide after sonicating for $5 \mathrm{~min}$ in an ultrasonic bath and the acetone allowed to evaporate. Optical microscopy was carried out using a bifocal microscope at 120x magnification with a Nikon digital camera.

\subsection{Vibration damping analysis.}

Samples were prepared for vibration analysis by coating metal substrates of dimensions 50 $\mathrm{x} 10 \times 1 \mathrm{~cm}$ with the test formulations. The coated beam was excited at various frequencies and the energy dissipation measured over a temperature range from $0-30^{\circ} \mathrm{C}$.

\subsection{RESULTS AND DISCUSSION}

\subsection{Microscopy}

In order to understand the effects of various fillers on the observed physical properties it is essential that the typical shapes of these materials are determined. The optical microscopy of barium sulphate (Figure (1A)) has a granular structure and a rough surface topography. The optical microscopy of Wollastonite (Figure(1B)) indicates that it exists as long needle of varying particle sizes and aspect ratios and confirm the data in Table (1).

\subsection{Rheology}

The effect of a filler on the polymer system to which they are added, depends critically on the nature of the dispersion which is initially achieved. In order to assess the effects of the 
fillers on the monomers, rheological measurements were carried out over shear rates from 0.6 to $600 \mathrm{~s}^{-1}$, as a function of filler concentration, Figure (2A).

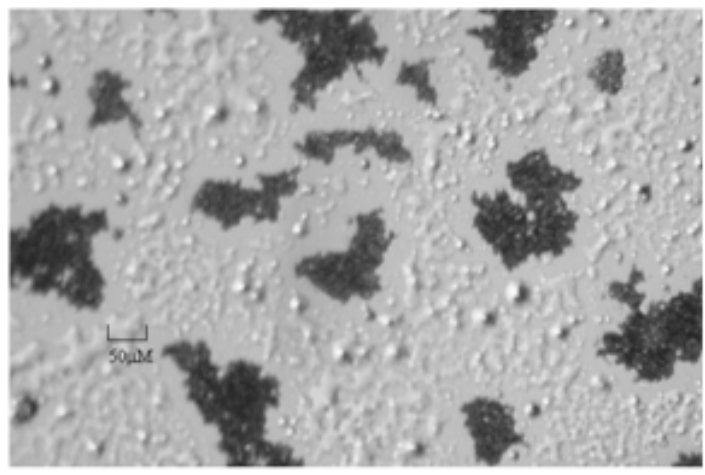

[A]

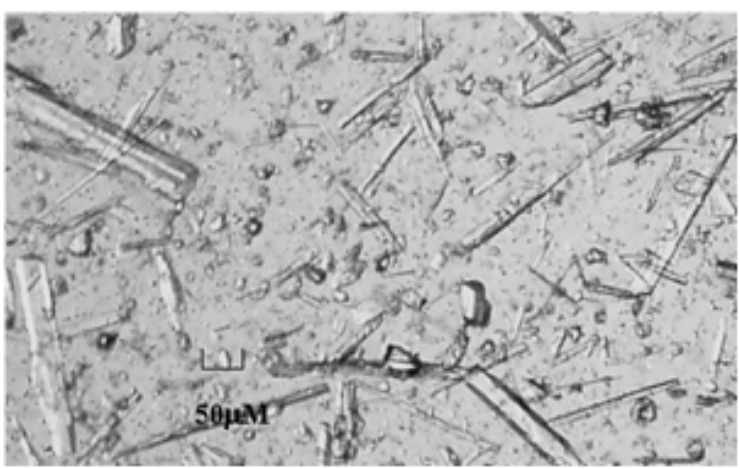

[B]

Figure (1) Optical Micrographs of the filler materials; [A] Barium Sulphate stirred with acetone; spherical particles and aggregates, [B] Wollastonite and Barium Sulphate sonicated with acetone for 10min, showing distribution of rod and spherical particles.

The addition of low levels of wollastonite to the poly(tetra-methylene glycol) up to 13 vol\%, has little effect on the viscosity of the system and little shear thickening is observed.

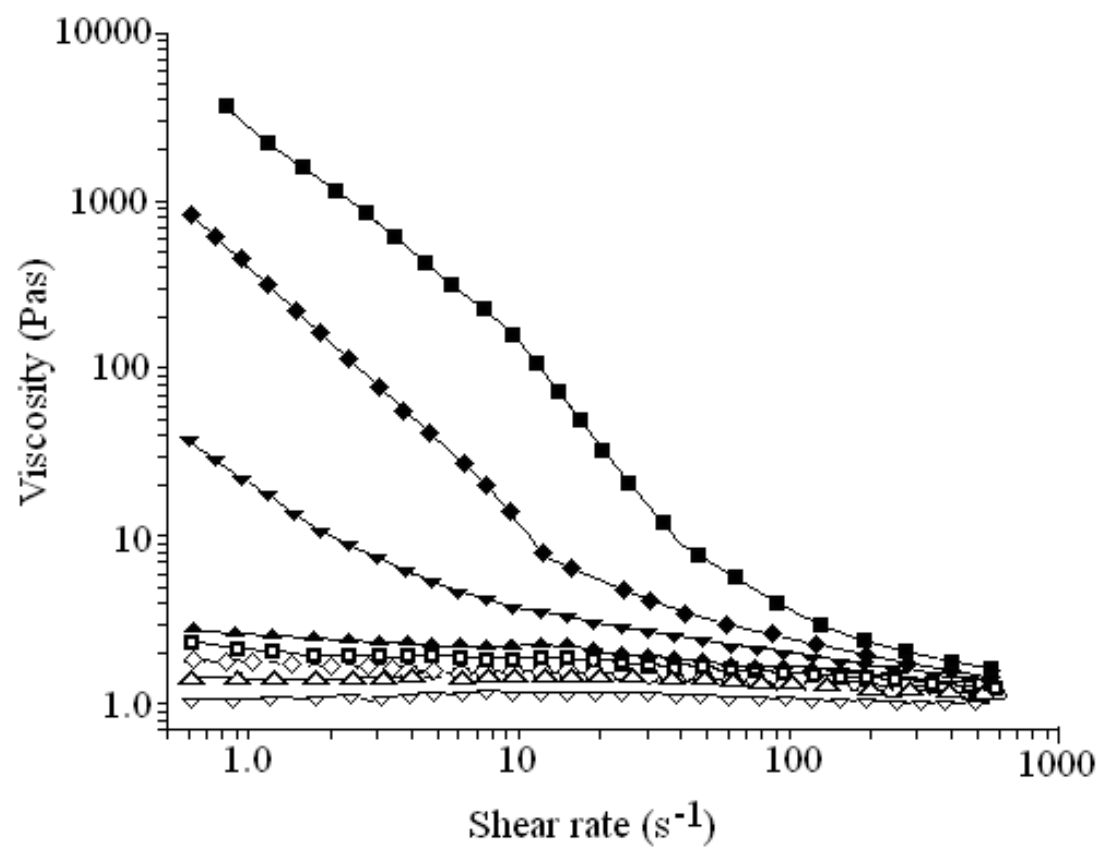

Figure (2) Increasing percentage of Wollastonite in polyol; Key:- -23.5 vol\%, -22.3 vol $\% ; \boldsymbol{\nabla}-21.2 \mathrm{vol} \% ; \boldsymbol{\Lambda}-20 \mathrm{vol} \%$, measurements with increasing shear rate $\left(0.6-600 \mathrm{~s}^{-1}\right)$ 
and $\square-23.5 \mathrm{vol} \%, \diamond-22.3 \mathrm{vol} \%, \nabla-21.2 \mathrm{vol} \%, \Delta-20 \mathrm{vol} \%$ with decreasing shear rate $\left(600-0.6 \mathrm{~s}^{-1}\right)$.

At higher loading levels $>20 \mathrm{vol} \%$, the initial viscosity at low shear rates is several orders of magnitude greater than that at high shear rates, indicating the thickening effect of filler on the polyol phase. The thickening effect is associated with filler - filler interactions creating a network structure in the liquid phase. Increasing the shear rate leads to a marked reduction in the viscosity and at a shear rate of $600 \mathrm{~s}^{-1}$, the viscosity is close to that of the polyol. Measurement of the sample which has been sheared and then the shear rate is reduced from $600-0.6 \mathrm{~s}^{-1}$ indicate values which are close to those of the polyol. This behaviour is indicative of the filler forming a temporary network which leads to the observed initial high viscosity but is reduced by flow alignment of the particles. The wollastonite with an aspect ratio typically of 20:1 is very effective in creating transient structures and enhances the viscosity at low shear rates. Repeating the experiments on dispersions which had been allowed to rest for five minutes indicated that the structure had almost completely recovered over this period. This enhancement in the low shear viscosity can potentially produce problems for mixing of the components to form the final reaction mixture.

In order to reduce the structure forming effects three samples of fillers with mixed shapes were prepared. The viscosity curves for these samples are shown in Figure (3). The addition of as little as $2.5 \mathrm{vol} \%$ of silica markedly reduces the ability for the wollastonite to form a network structure and decreases the initial value of the low shear viscosity. The addition of the barium sulphate leads to a further reduction in the low shear viscosity and a lower shear dependence. The apparent increase in the high shear values reflects the higher solid loading of the system. It is envisaged that the silica particles interfere with the structure build up of the wollastonite fibres, and acts as a lubricant easing the relative movement of the fibres passed one another hindering the build up of the structure. The addition of barium sulphate decreases the initial viscosity still further. 
The rheological studies indicate that the critical level for the addition of wollastonite is $\sim 20$ vol\%, although the network forming tendency of this filler in liquid dispersions can be reduced by the addition of small amounts of spherical fillers, hence allowing the total solids content to be significantly increased in the formulations without encountering mixing problems.

\subsection{Relaxation behaviour of filled systems}

The principal aim of this investigation was to explore the effects of the functionality of the isocyanate, effects of cross linker and possible interactions with fillers on the energy loss characteristics of the PU matrix composites. In the design of a final material all the influences can be brought into play in adjusting the characteristics of the composite to be fit for purpose.

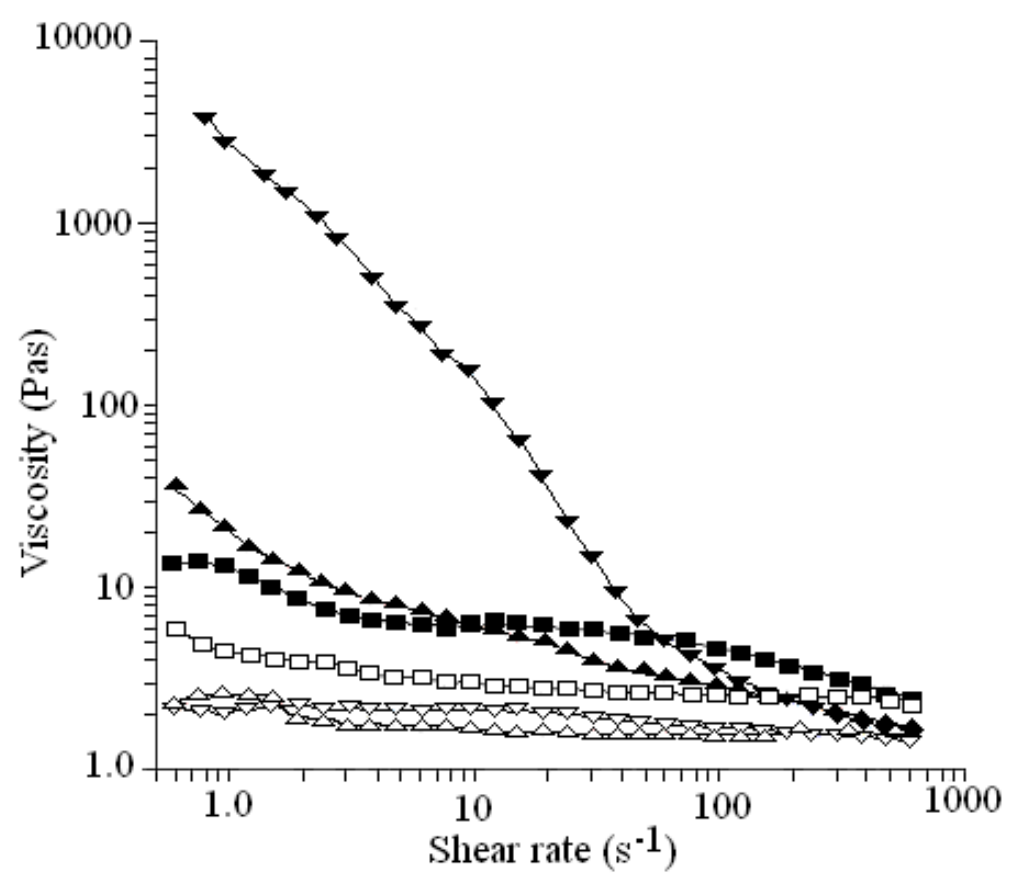

Figure (3) Variation of viscosity with shear rate of initial samples, with sample $1 ; \boldsymbol{\nabla}(0.6-$ $\left.600 \mathrm{~s}^{-1}\right)$ and $\nabla\left(600-0.6 \mathrm{~s}^{-1}\right)$ flow curves. Sample $2 ; \boldsymbol{\Delta}\left(0.6-600 \mathrm{~s}^{-1}\right)$ and $\Delta\left(600-0.6 \mathrm{~s}^{-1}\right)$ flow curves. Sample $3 ; \boldsymbol{\square}\left(0.6-600 \mathrm{~s}^{-1}\right)$ and $\square\left(600-0.6 \mathrm{~s}^{-1}\right)$ flow curves. 
Sample 1 represents a 23.5 vol\% of wollastonite; sample 2, contains 1.0 vol\% of silica, $23.2 \%$ wollastonite and sample 3 , contains $21.7 \mathrm{vol} \%$ of wollastonite, 0.99 vol\% silica, 6.4 vol\% barium sulphate (spherical form).

\subsubsection{Effect of filler on the PU matrix relaxation}

Dielectric relaxation and DMTA measurements were performed on a Hyperlast M143: polyol of unfilled and uncross linked PU matrix (Figure (4)). The main feature in the dielectric spectrum, is a strong dipolar relaxation feature associated with the reorientation of the ether linkage of the poly(tetramethyleneoxide)- TMO segment.

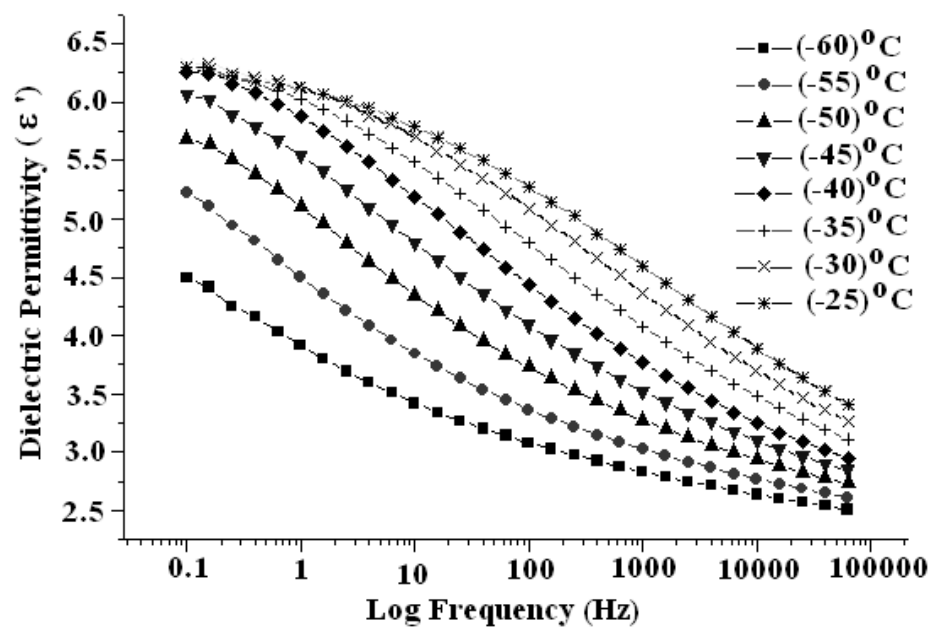

[A]

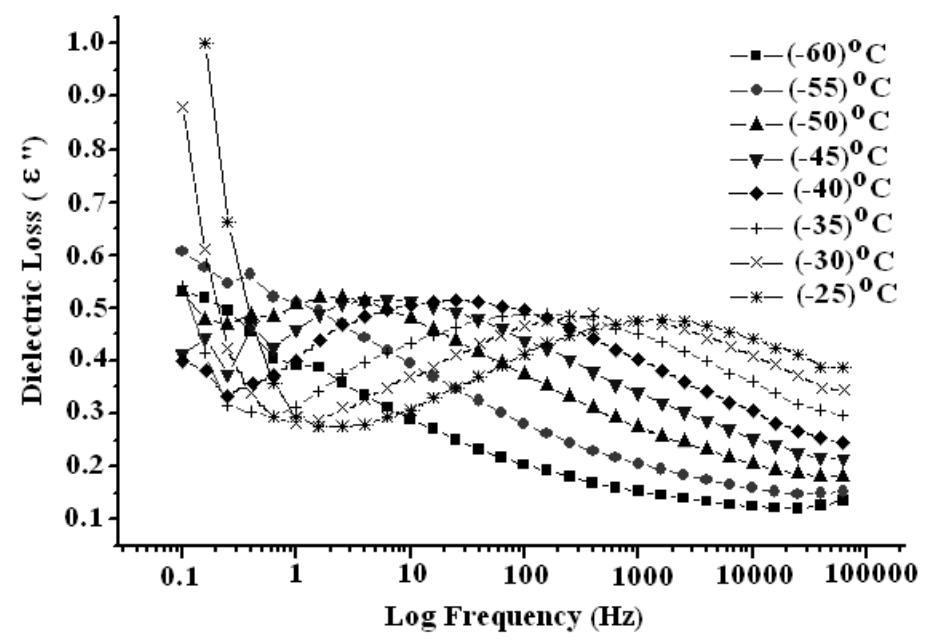

[B] 


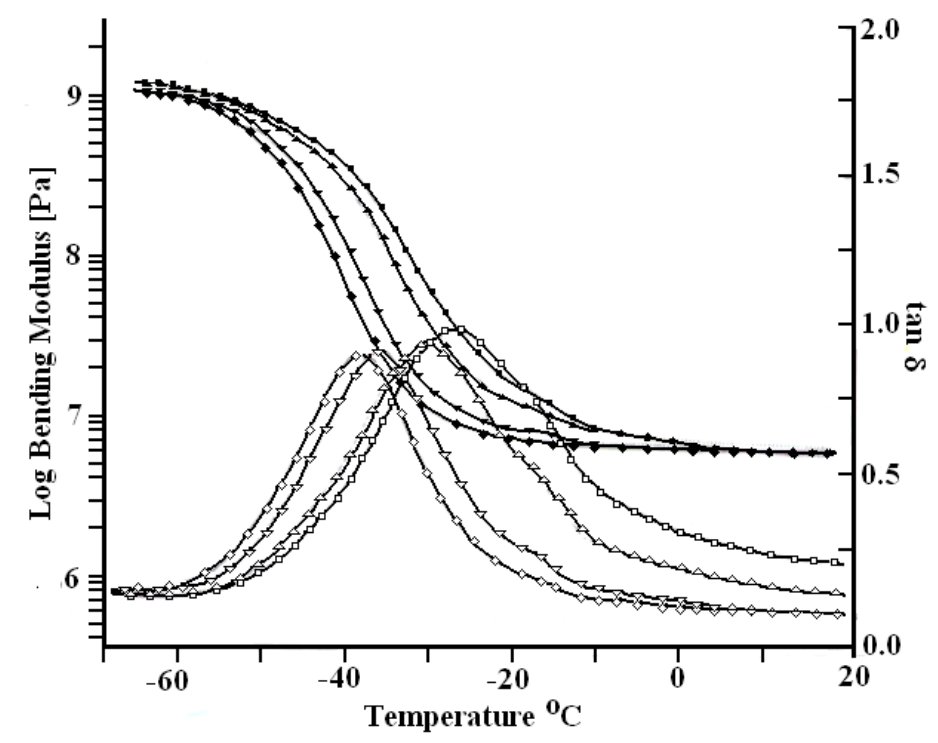

$[\mathrm{C}]$

Figure (4) Dielectric relaxation permittivity $[\mathrm{A}]$ and loss [B] as a function of temperature between $213 \mathrm{~K}$ and $248 \mathrm{~K}$ and multi frequency DMTA [C] for unfilled uncrosslinked PU. Key for dielectric measurements:- $-60^{\circ} \mathrm{C},-55^{\circ} \mathrm{C}, \boldsymbol{\Delta}-50^{\circ} \mathrm{C}, \boldsymbol{\nabla}-45^{\circ} \mathrm{C},+-35^{\circ} \mathrm{C}, \mathrm{x}-$ $30^{\circ} \mathrm{C},{ }^{*}-25^{\circ} \mathrm{C}$. Key for DMTA measurements:- Modulus at $-0.3 \mathrm{~Hz}, \boldsymbol{\nabla}-3 \mathrm{~Hz}, \boldsymbol{\Delta}-10$ $\mathrm{Hz}$, and $\mathbf{\square}-30 \mathrm{~Hz}$ and loss:- $\diamond-0.3 \mathrm{~Hz}, \nabla-3 \mathrm{~Hz}, \Delta-10 \mathrm{~Hz}, \square-30 \mathrm{~Hz}$.

The relaxation spreads over three decades of frequency and is typical of a simple thermally activated segmental reorientation process. The sharp rise in the dielectric loss at very low frequencies is associated with ionic conduction in the material and increases in amplitude as the temperature is increased. The corresponding DMTA traces are shown in Figure (4C). From the shift of the dielectric or mechanical loss peak with temperature it is possible to determine the Arrhenius activation energy for the segmental reorientation of the TMO segment which dictates the temperature dependence of the energy dissipation. The linearity of the Arrhenius plot (Figure (5)), indicates that the process is thermally activated and values of the derived energy are presented in Table (2). It is apparent that wollastonite has the ability to interact strongly with the PU matrix and significant shifts are observed in the relaxation frequency plot and the temperature dependence with increasing filler content. Interestingly, barium sulphate does not appear to shift the relaxation in the same way reflecting significantly weak interactions between PU and filler. It is clear that the barium 
sulphate has little effect on either the dynamic mechanical or dielectric relaxation of the resin.

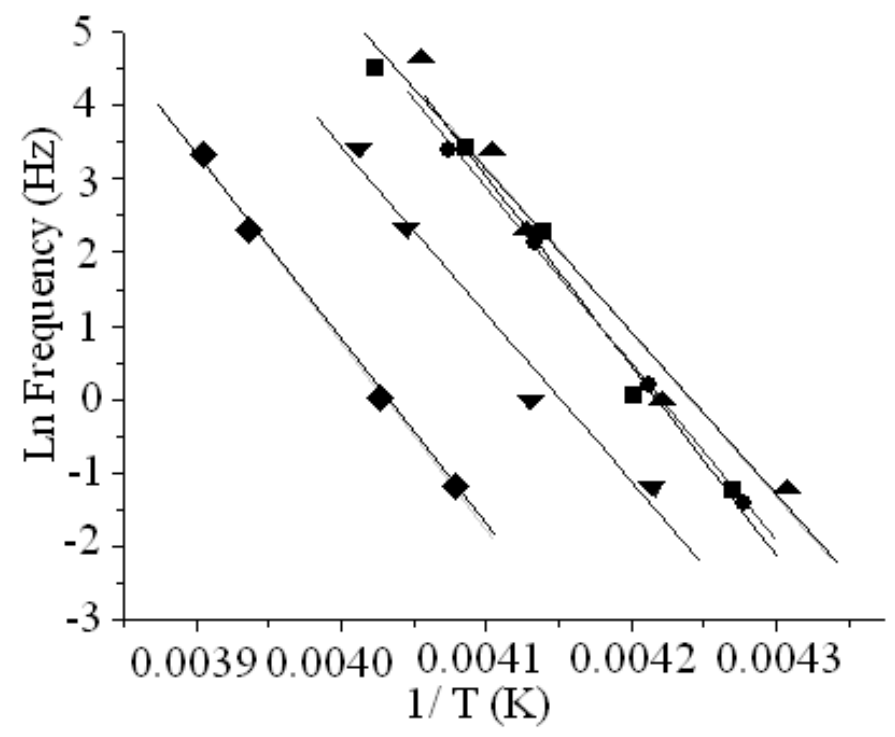

Figure (5) Arrhenius plots for the dielectric relaxation data for various filled PU composites. Key:- $\mathbf{\square}$ - unfilled PU, - - 3wt $\%$ Barium sulphate, $\boldsymbol{\Delta}$ - $6 \mathrm{wt} \%$ Barium sulphate, $\boldsymbol{\nabla}$-3wt $\%$ wollastonite, $-6 \mathrm{wt} \%$ wollastonite.

\begin{tabular}{|l|l|l|l|}
\hline $\begin{array}{l}\text { Wollastonite } \\
\text { by \% volume }\end{array}$ & $\begin{array}{l}\mathrm{BaSO}_{4} \\
\text { by \% volume }\end{array}$ & $\begin{array}{l}\text { Aerosil 200 } \\
\text { by \% volume }\end{array}$ & $\begin{array}{l}\text { Activation Energy } \\
\mathrm{kJ} \mathrm{mol}^{-1}\end{array}$ \\
\hline 0 & 0 & 0 & $223 \pm 25$ \\
\hline 3 & 0 & 0 & $200 \pm 25$ \\
\hline 6 & 0 & 0 & $185 \pm 25$ \\
\hline 0 & 3 & 0 & $189 \pm 25$ \\
\hline 0 & 6 & 0 & $214 \pm 25$ \\
\hline
\end{tabular}

Table (2) Variation of activation energy with filler content.

This is confirmed in the dielectric relaxation with a shift towards higher temperatures and the activation energy at $6 \mathrm{wt} \%$ wollastonite increases significantly suggesting interaction of the TMO segments with the surface of the wollastonite fibre. Normally interaction between the polymer and the surface tightens the matrix and increases the activation energy and this does not appear to be the case with the TMO PU elastomers. It has been observed in other systems that a shift in the relaxation is observed without change in the activation energy and this can be attributed to 'energy starvation'. Since the relaxation is thermally activated the probability of reorientation occurring depends on the energy being fed into the 
reorientational motion. It appears that the weak interactions between the ether linkages and the filler allow the filler to act as a heat sink and reduce the pre-exponential factor in the Arrhenius equation. The reduced energy flow produces a lower probability of activation of the reorientational process and a shift of the relaxation feature along the temperature axis.

\subsubsection{Effect of crosslinker.}

The increasing levels of cross linker TMP will influence the ability for MDI to form a hard phase structure and leads to changes in the density of packing and also changes the dielectric relaxation behaviour (Figure (6)) .

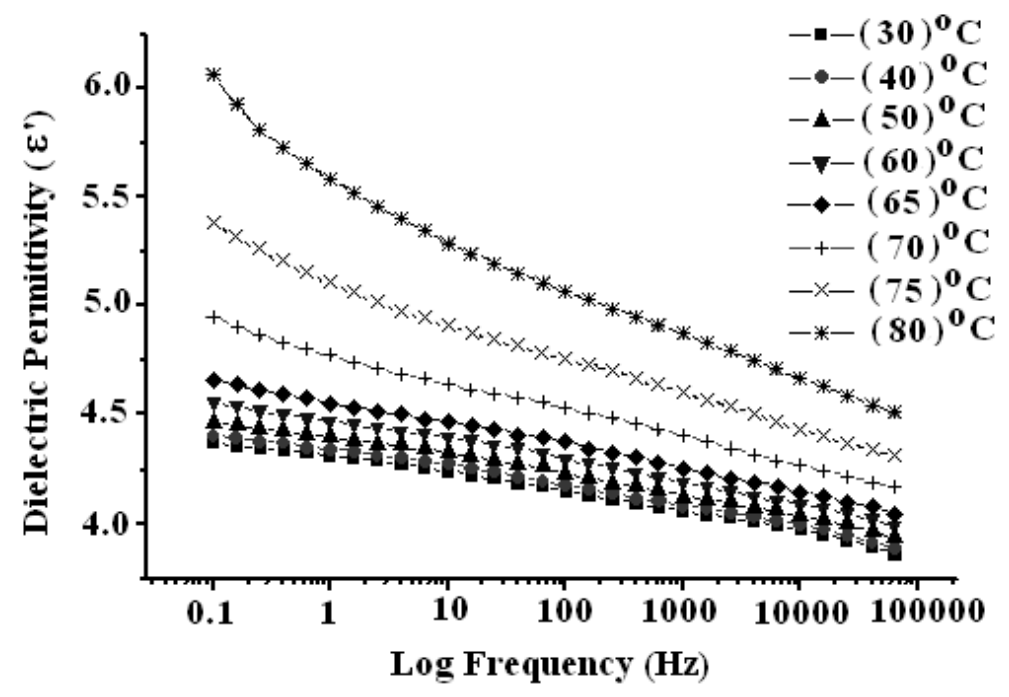

[A]

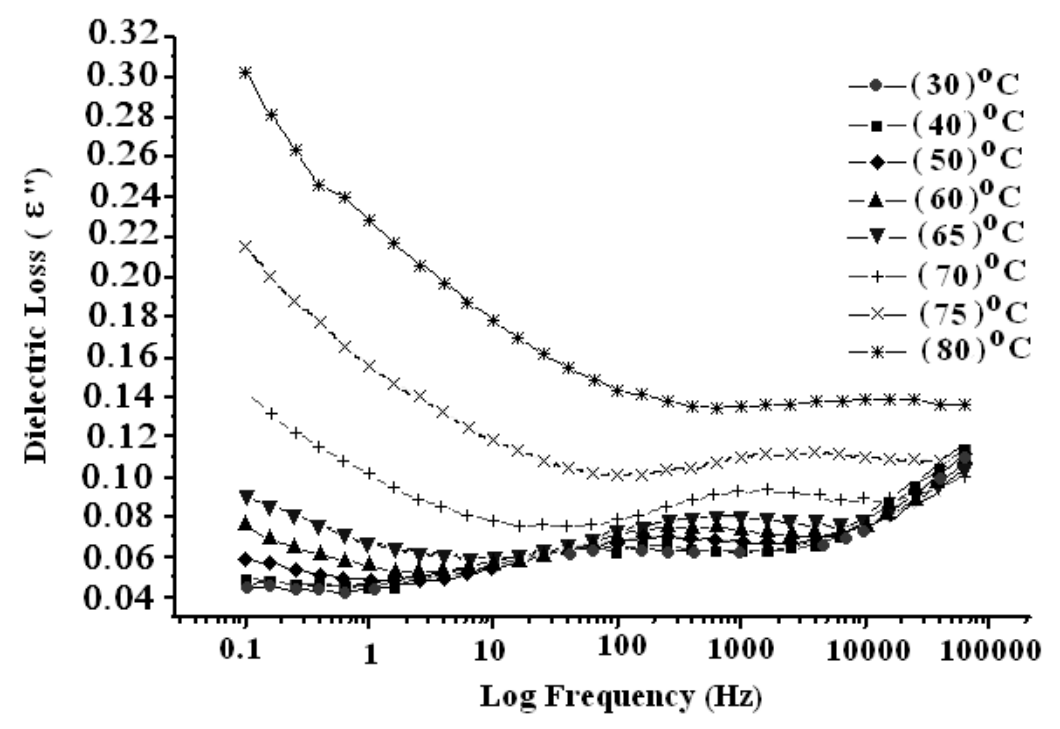


Figure (6) Dielectric permittivity [A] and dielectric loss [B] for $10 \%$ cross linked PU system. Key:- $-30^{\circ} \mathrm{C},-40^{\circ} \mathrm{C},-50^{\circ} \mathrm{C}, \boldsymbol{\Delta}-60^{\circ} \mathrm{C},+-70^{\circ} \mathrm{C}, \mathrm{x}-75^{\circ} \mathrm{C} *-80^{\circ} \mathrm{C}$.

The change in the distribution of MDI structural types will impact on the nature of the distribution of TMO which will consequently broaden the dipole relaxation and consequently reduce the temperature dependence of the overall process. The phase separated nature of the PU leads to observation of polarization effects associated with the heterogeneous nature of the polymer. Ionic impurities can migrate within the polymer and become trapped at the interfaces created by the phase separated MDI and gives rise to the so-called Maxwell Wagner Sillars process. Unfortunately, this latter process dominates the low frequency relaxation region (Figure (6)) and makes analysis of the breadth of the dipolar relaxation associated with the ether segments difficult. The relaxation can be seen as the broad peak in the dielectric loss in Figure (6B). The polyurethane entities are phase separated, and because they are extensively hydrogen bonded will not contribute to the dipole relaxation until the hard phase 'melts', which occurs at $\sim 150^{\circ} \mathrm{C}$. It is however clear from the plots that the relaxation is broad and extends over several decades of frequency. The DMTA analysis gives a direct indication of the mechanical properties and was used to explore the effects of changes of filler and crosslinker.

\subsection{Dynamic Mechanical Thermal Analysis}

\subsubsection{Effects of filler}

Damping of metallic structures depends on the efficiency of being able to couple energy into the structure and is primarily controlled by being able to match the modulus of the coating layer to that of the substrate. Wollastonite is a fibrous material with an aspect ratio of 20:1; and a small volume fraction of fibres can increase both the low and high temperature modulus of the system (Figure (7)) which will improve the match with the rigid substrate. The high temperature modulus is determined by two factors; the extent of cross linking in the material and the degree of interaction between matrix and filler. Barium sulphate at low levels of addition has little effect on the high temperature modulus or $\tan \delta$ 
indicating relatively weak interaction between filler and matrix. In contrast, wollastonite shifts the relaxation to higher temperatures showing significant interaction between the fibre surface and the resin matrix.

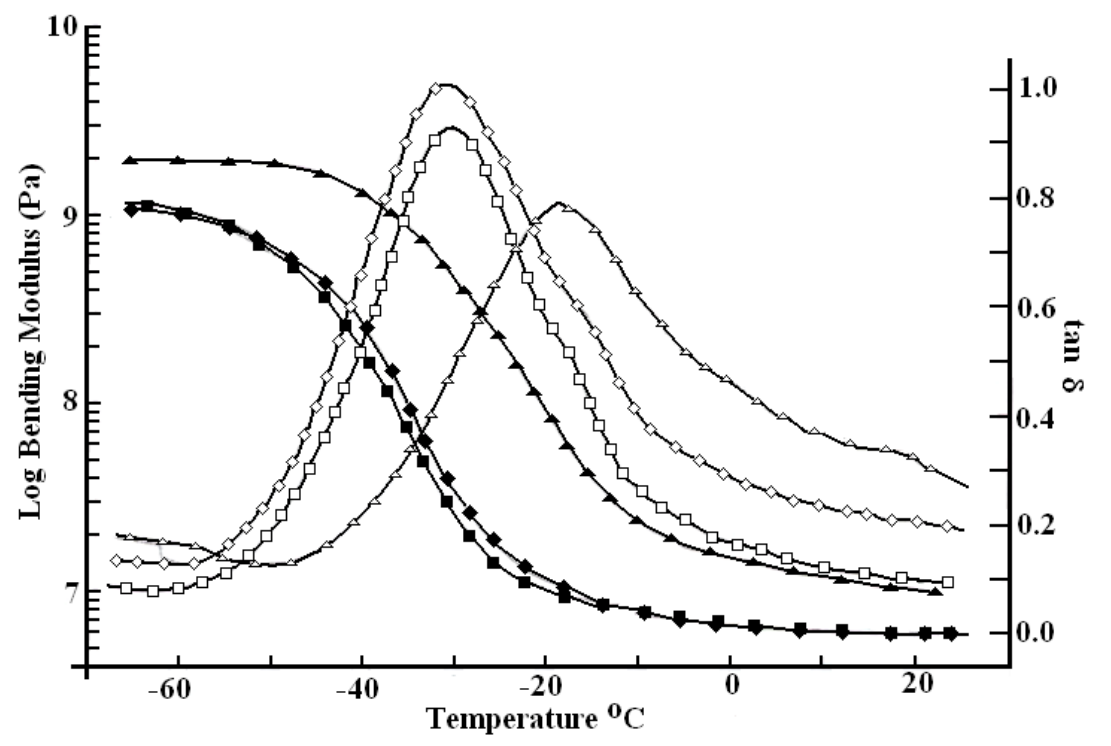

Figure (7) DMTA of uncrosslinked system with $6 \mathrm{w} / \mathrm{v} \% \mathrm{BaSO}_{4}$ and $6 \mathrm{w} / \mathrm{v} \%$ Wollastonite. Key:- Modulus - $\mathbf{-}$ - unfilled PU, - $6 \mathrm{wt} / \mathrm{v} \% \mathrm{BaSO}_{4}, \boldsymbol{\Delta}$-6wt/v\% Wollastonite; Loss $\square-$ unfilled PU, $\diamond-6 \mathrm{wt} / \mathrm{v} \% \mathrm{BaSO}_{4}, \Delta-6 \mathrm{wt} / \mathrm{v} \%$ Wollastonite.

\subsubsection{Effect of change of functionality of the MDI}

A series of experiments were conducted on materials created with high and low functional MDI. Figure (8) shows the variation in E' and $\tan \delta$ with variation in the level of cross linker. The most notable difference between the MDIs is the breadth of the relaxation; with the high functionality MDI giving $\tan \delta$ significantly broader than the lower functionality MDI. The increase in breadth is a consequence of the greater variety of structures generated by the use of polymeric MDI for the TMO. The isocyanate is partially inhibited in packing to form the organised hard phase structure which predominates in the lower functional MDI. The variation in the environments is reflected in the breadth in the relaxation process being increased. The crosslinker will tighten up the matrix and this is reflected in a shift in the $\tan \delta$ to higher temperatures and further broadening of the loss peak. Change of the level of the crosslinker allows the peak to be shifted form from $\sim-5^{\circ} \mathrm{C}$ for $6 \%$ TMP to a 
value of $\sim 50^{\circ} \mathrm{C}$ for $14 \%$ of TMP. From the point of view of matching of the peak to the optimum value for the damping of the vibration changing of the level of crosslinker is a relatively simple procedure.

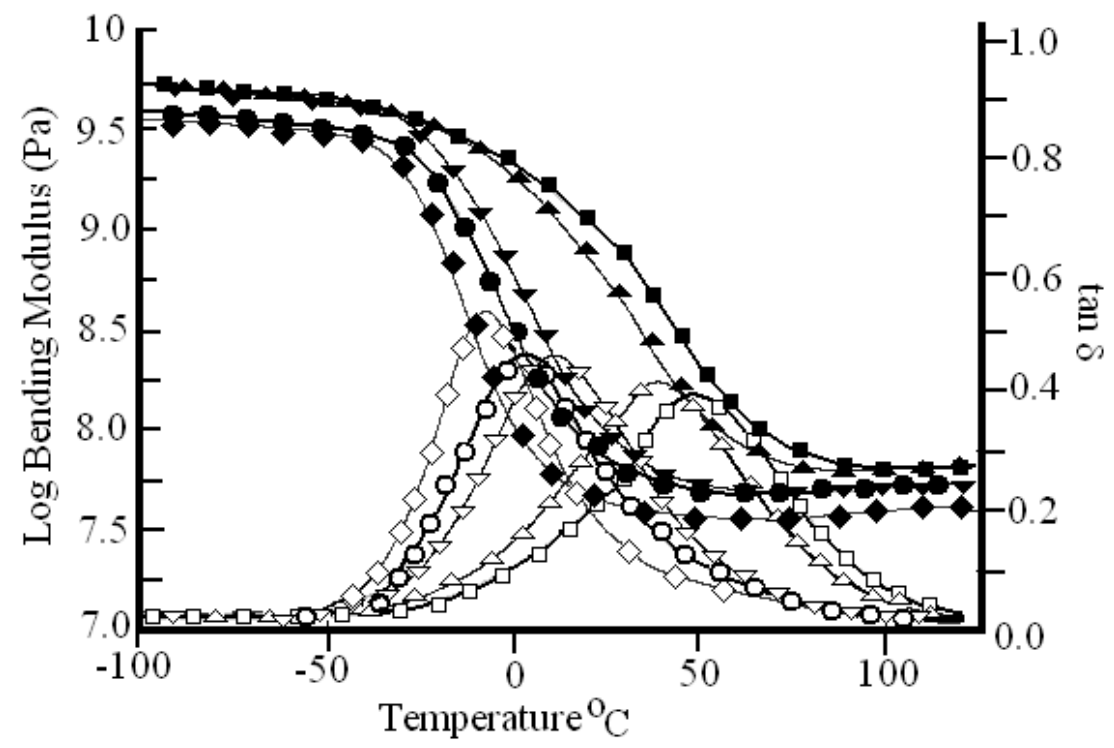

[A]

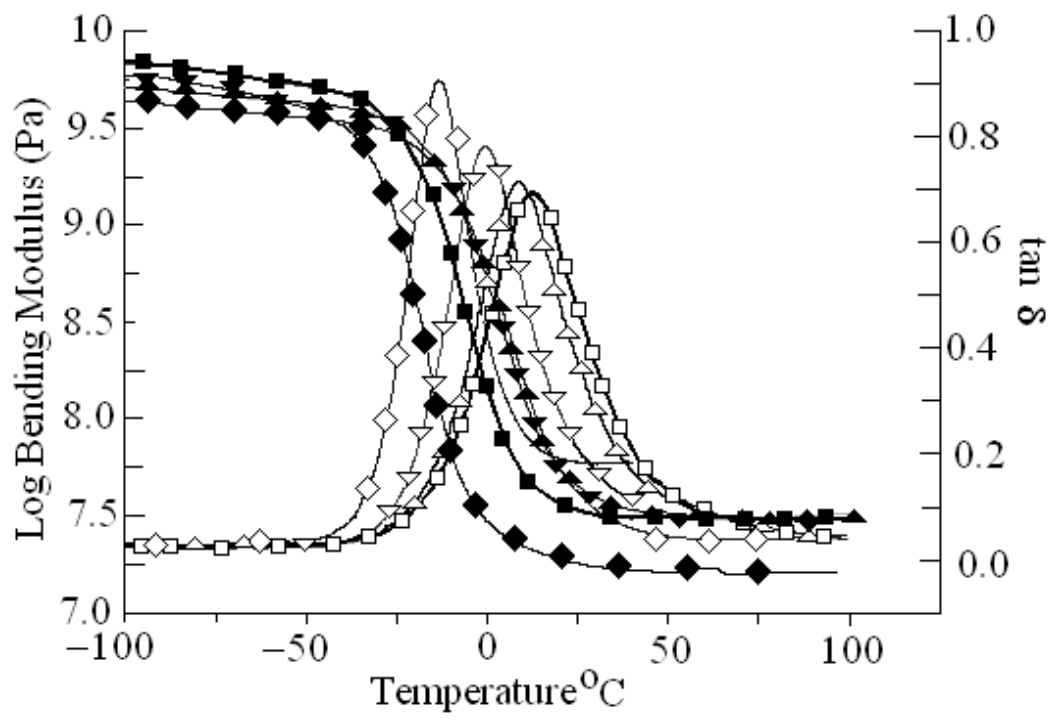

[B]

Figure (8) DMTA traces for various levels of crosslinker (trimethylolpropane) TMP with [A] Suprasec MDI, functionality - 2.7, Key:- Modulus • - 4\% TMP, • - 6\% TMP, $\nabla$ $8 \% \Delta-12 \%$ and $-14 \%$, Loss $\diamond-4 \%, \circ-6 \%, \nabla-8 \%, \Delta-12 \%$ and and $\square-14 \%$. [B] Hyperlast MDI, functionality - 2, Key:- Modulus $-6 \%, \mathbf{\square}-10 \%, \boldsymbol{\Delta}-12 \%, \boldsymbol{\nabla}-14 \%$, Loss $\diamond-6 \%, \square-10 \%, \Delta-12 \%, \nabla-14 \%$. 
The effect of variation of the level of crosslinker for the Hyperlast MDI was also investigated. The Hyperlast MDI is created by end capping a TMO polymer and has a functionality of two. Polymerisation with the TMO will create a very regular structure which phase separates to form regions of polyurethane which are extensively hydrogen bonded. The phase separation produces a well defined environment for the TMO and the relaxation which is observed is fairly narrow (Figure (8B)). As in the case of the polymeric MDI the crosslinker TMP will increase the variety of environments experienced by the TMO and this is reflected in a broadening of the relaxation peak and a shift to higher temperatures. The effects of the crosslinker as less marked than with the polymeric MDI, the peak being shifted from a temperature of $\sim-20^{\circ} \mathrm{C}$ to $20^{\circ} \mathrm{C}$ by the addition of $8 \%$ of TMP. However as in the case of the polymeric MDI the possibility of tuning the peak to a particular temperature is also possible.

\subsubsection{Combining filler and cross linked effects}

It is apparent that changes in the damping behaviour can be achieved by either variation of the type of filler or the level of cross linker (Figure (9)).

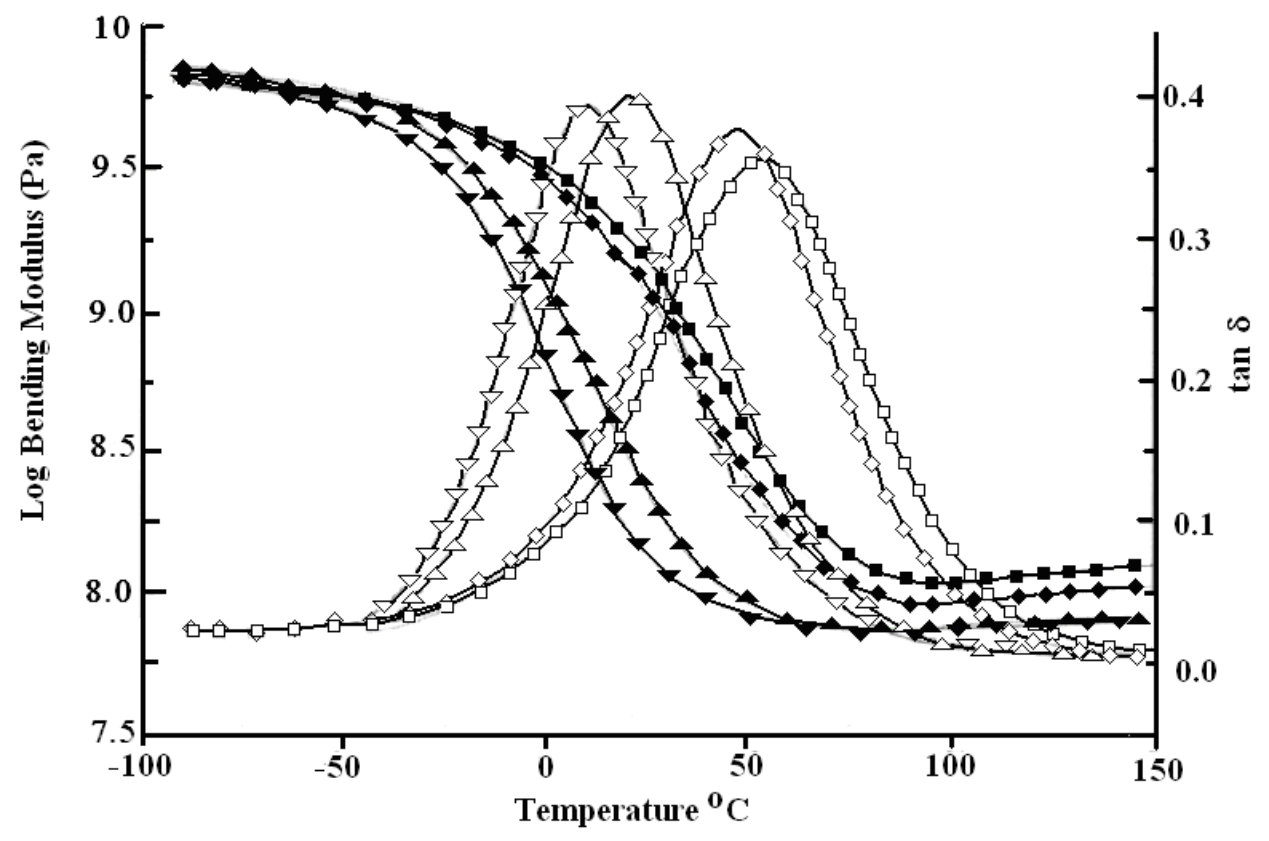


Figure (9) The DMTA traces for Suprasec 5005, with 6vol\% Wollastonite with variation in cross linker TMP, Key:- Modulus $\nabla-6 \%$ TMP, $\boldsymbol{\Delta}-8 \%$ TMP, - $12 \%$ and $-14 \%$, Loss

$$
\Delta-6 \%,-6 \%, \nabla-8 \%, \Delta-12 \% \text { and and } \square-14 \% \text {. }
$$

Increasing the level of the crosslinker TMP has the expected effect of increasing the temperature at which the loss peak is observed for the $6 \mathrm{vol} \%$ Wollastonite filled material. The shift is clearly related to the effect of the crosslinker which is not significantly influenced by the presence of the fibrous Wollastonite filler.

To explore the effect of variation of the filler, samples were created at low - $6 \%$ and higher $-14 \%$ crosslinker level and with variation of the filler type (Figure (10)).

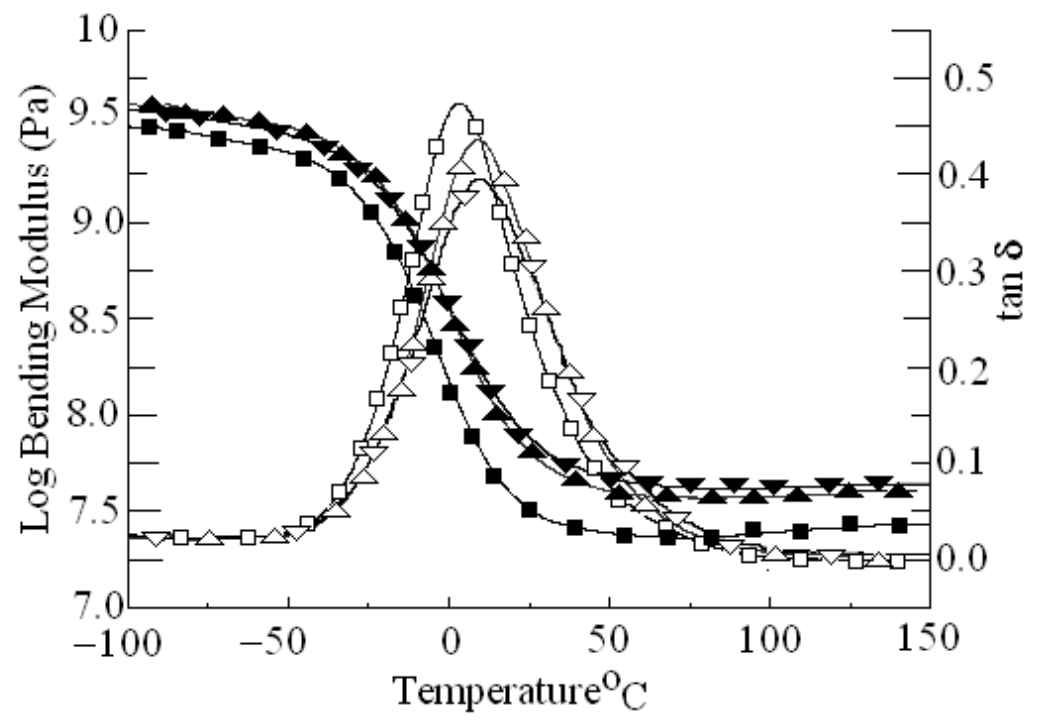




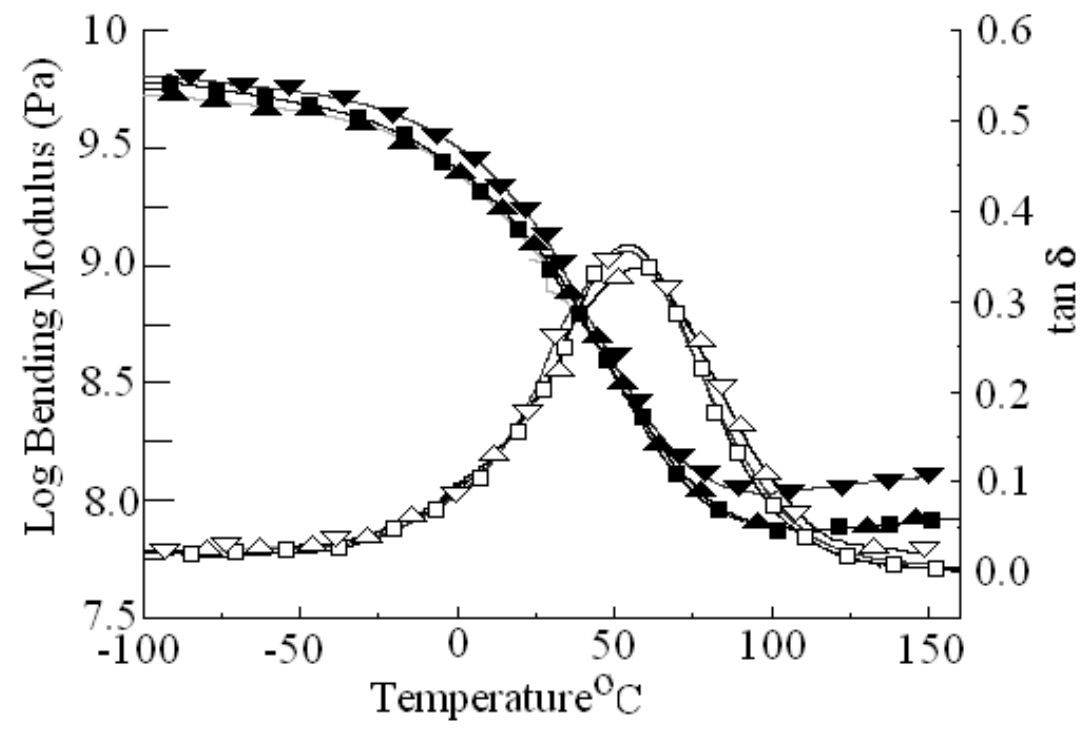

[B]

Figure (10) The DMTA traces for Suprasec 5005, with Wollastonite, Wollastonite and barium Sulphate and Wollastonite with talc. [A] low crosslinker density 6\% TMP. Key:Modulus - Wollastonite, $\boldsymbol{\Delta}$ - Wollastonite + Barium sulphate, $\boldsymbol{\nabla}$ - Wollastonite + talc. Loss $\square-$ Wollastonite, $\Delta-$ Wollastonite + Barium sulphate, $\nabla$ - Wollastonite + talc. [B] high crosslinker density -14\% TMP, Key:- Modulus - Wollastonite, $\boldsymbol{\Delta}$ - Wollastonite + Barium sulphate, $\boldsymbol{\nabla}-$ Wollastonite + talc. Loss $\square-$ Wollastonite, $\Delta-$ Wollastonite + Barium sulphate, $\nabla$ - Wollastonite + talc.

It is apparent that variation of the filler type has a very small effect on the location of the relaxation which is controlled primarily by the level of cross linker which is incorporated in the matrix. The insensitivity to the type of filler therefore allows both the level and the filler to be varied to achieve a better match between the substrate and the absorber for damping applications.

\subsubsection{Vibration damping behaviour of the filled PU matrix materials.}

Using the above data a series of beams were prepared and explored to determine the damping characteristics. An example of the data obtained for a sample that contains 22vol $\%$ of Wollastonite, $20 \mathrm{vol} \%$ of barium sulphate and $6 \%$ cross linker as shown in Figure (11). 


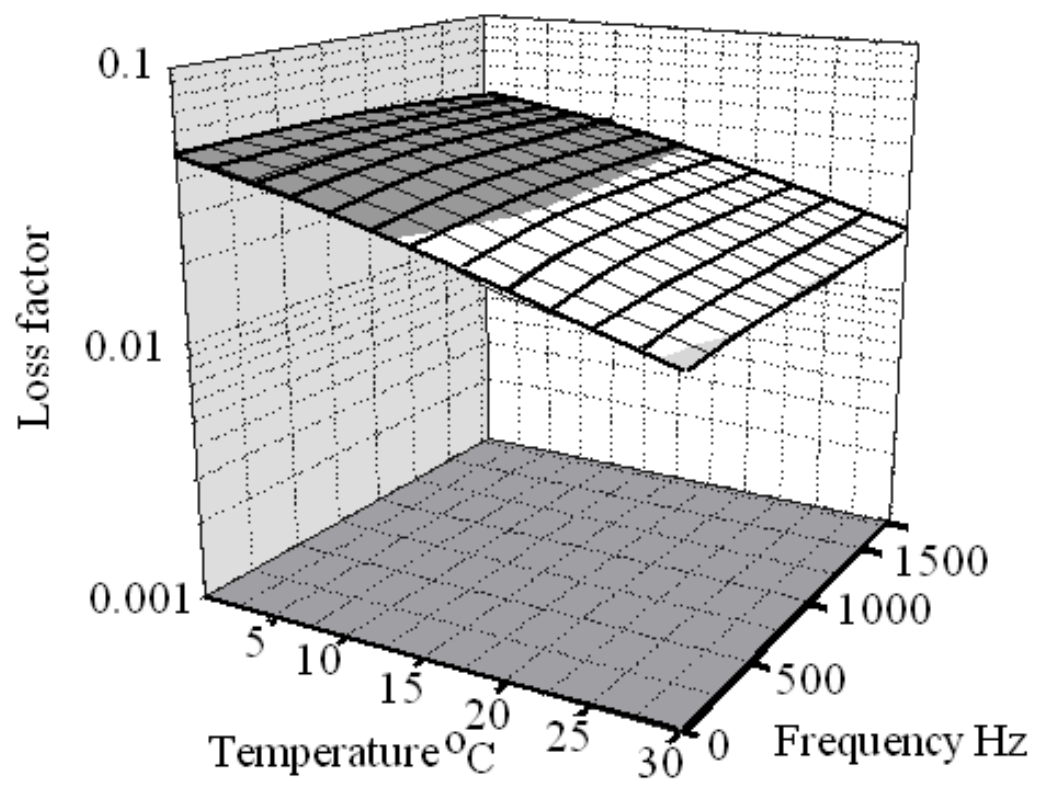

Figure (11) Plots of the loss factor, frequency and temperature dependence of the loss factor for a matrix composed of $22 \mathrm{vol} \%$ of Wollastonite, $20 \mathrm{vol} \%$ of barium sulphate and $6 \%$ cross linker.

Over the frequency range $1 \mathrm{~Hz}$ to $1500 \mathrm{~Hz}$ and over the temperature range 0 to $30^{\circ} \mathrm{C}$ there is a significant damping of the vibration. The observed behaviour is consistent with the predictions from the DMTA data that this formulation would have a loss feature which spans the frequency and temperature range. It is apparent that the interaction between the PU and the metallic substrate has aided the achievement of the desired breadth of vibration damping. This example illustrates the ability to design damping systems with a broad frequency response based on data obtained using DMTA data.

\section{CONCLUSIONS}

This study illustrates how by changing the formulation of the PU it is possible to change the location, breadth and amplitude of the mechanical loss to suit the requirements of a material for effective vibration damping. This study has therefore a large number of potential applications in the use of materials for damping a variety of structures used in mechanical engineering applications. 
For effective vibration damping the material requires to have a good impedance match to the substrate and this requires control of the density and the modulus of the material. By appropriate selection of the barium sulphate, which imparts a significant density increase and Wollastonite which helps control the loss characteristics and the location of the loss feature and enhancement of the stiffness - bending modulus. A striking feature which emerges form this study is the ability to shift the loss feature by use of cross linker, but the loss characteristics are sensitive to the nature of the isocyanate used. The polymeric isocyanate with its restricted ability to pack is influenced more extensively by the addition of the cross linker than the simpler chain extended isocyanate. The low temperature dependence is a result of the broad distribution of environments in which the TMO exists at a molecular level. The chain extended isocyanate tends to be more effective at phase separation and exhibits narrower loss features which will result in a greater sensitivity of the loss to temperature.

\section{Acknowledgements}

The authors wish to acknowledge the support of EPSRC for part of the period of this research.

\section{References}

(1) Burke M, Townend D.J., Acoustic and mechanical properties of polyurethanes based on polybutadiene soft segment, Plastics Rubber and Composites 28 (1999) 185.

(2) Simplified models of the vibration of mannequins in car seats, Kim SK, White SW, Bajaj AK, Davies P, J. Sound \& Vibration 264 (2003) 49.

(3) Flexible polyurethane foam modelling and identification of viscoelastic parameters for automotive seating applications, Deng R, Davies P, Bajaj AK, J. Sound \&Vibration 262 (2003) 391.

(4) Modelling compressive cyclic stress-strain behaviour of structural foam, Shen Y, Golnaraghi F, Plumtree A, International J. of Fatigue 23 (2001) 491

(5) S.W. Hudnut and D.D.L. Chung, Use of submicron diameter carbon filaments for reinforcement between continuous carbon- fibre layers in a polymer-matrix composite, Carbon, 33 (1995) p1626 
(6) W. Fu and D.D.L. Chung, Vibration reduction ability of polymers, particularly polymethylmethacrylate and polytetrafluoroethylene, Polym. Polym. Compos, 6 (2001) p 423.

(7) X. Luo and D.D.L Chung,. Vibrational damping using flexible graphite. Carbon, 38 (2000) p1510

(8) M. Song, D.J. Hourston, and F-U Schafer, Correlation between mechanical damping and interphase content in interpenetrating polymer networks J. Appl. Poly. Sci., 81 (2001) p2439

(9) H.H. Chu, C.M. Lee and W.G. Huang, Damping of vinyl acetate-n-butyl acetate copolymers, J. Appl. Poly. Sci., 91 (2004) p1396

(10) D.D.L. Chung, Review: Materials for vibrational damping, J. Mat. Sci, 36 (2001) p5733

(11) W.B. Huang and F.C Zhan, Studies on the dynamic-mechanical and vibration damping properties of polyether urethane and epoxy composites, J. Appl. Poly. Sci., 50 (1993) p227

(12) C.J. Tung and C.J. Hsu. Vibration damping with urethane acrylate simultaneous semiinterpenetrating polymer networks, J. Appl. Poly. Sci., 46 (1992) p1759

(13) J. Kylma and J. Seppala, Ternary-phase poly(ester-urethane)/elastomers/filler composites, J. Appl. Poly. Sci., 79 (2001) p1531

(14) C. Delides, R. A. Pethrick European Polymer J. 17 (1981) 675

(15) Characterization of Polyurethane Elastomers by C-13 Nmr-Spectroscopy, C. Delides, R. A. Pethrick A. V. Cunliffe, P. G. Klein Polymer 22 (1981) 1205

(16) T.K. Kundu, K. Hanumantha Rao and S.K. Parker, Atomistic simulation of the surface structure of wollastonite. Chem. Phys. Let. 337 (2003) p81 